\title{
Dietary intake of different types and characteristics of processed meat which might be associated with cancer risk - results from the 24-hour diet recalls in the European Prospective Investigation into Cancer and Nutrition (EPIC)
}

\author{
Jakob Linseisen ${ }^{1, *}$, Sabine Rohrmann ${ }^{1}$, Teresa Norat ${ }^{2}$, Carlos A Gonzalez ${ }^{3}$,
} Miren Dorronsoro Iraeta ${ }^{4}$, Patrocinio Morote Gómez ${ }^{5}$, Maria-Dolores Chirlaque ${ }^{6}$, Basilio G Pozo 7 , Eva Ardanaz ${ }^{8}$, Irene Mattisson 9 , Ulrika Pettersson 9 , Richard Palmqvist ${ }^{10}$, Bethany Van Guelpen ${ }^{11}$, Sheila A Bingham ${ }^{12}$, Alison McTaggart ${ }^{13}$, Elizabeth A Spencer ${ }^{14}$, Kim Overvad ${ }^{15}$, Anne Tiønneland ${ }^{16}$, Connie Stripp ${ }^{16}$, Françoise Clavel-Chapelon ${ }^{17}$, Emmanuelle Kesse ${ }^{17}$, Heiner Boeing ${ }^{18}$, Kerstin Klipstein-Grobusch ${ }^{18}$, Antonia Trichopoulou ${ }^{19}$, Effie Vasilopoulou ${ }^{19}$, George Bellos ${ }^{20}$, Valeria Pala ${ }^{21}$, Giovanna Masala ${ }^{22}$, Rosario Tumino 23 , Carlotta Sacerdote ${ }^{24}$, Mariarosaria Dél Pezzo 25 , H Bas Bueno-de-Mesquita ${ }^{26}$, Marga C Ocke ${ }^{26}$, Petra HM Peeters ${ }^{27}$, Dagrun Engeset ${ }^{28}$, Guri Skeie $^{28}$, Nadia Slimani ${ }^{2}$ and Elio Riboli ${ }^{2}$

${ }^{1}$ German Cancer Research Centre, Division of Clinical Epidemiology, Im Nevenheimer Feld 280, D-69120 Heidelberg, Germany: ${ }^{2}$ International Agency for Research on Cancer, Unit of Nutrition, Lyon, France:

${ }^{3}$ Department of Epidemiology, Catalan Institute of Oncology, Barcelona, Spain: ${ }^{4}$ Department of Health of the Basque Government, Public Health Division of Gipuzkoa, San Sebastian, Spain: ${ }^{5}$ Health Council and Health Services Asturias, Public Health Directorate, Oviedo, Spain: ${ }^{6}$ Epidemiology Department, Health Council of Murcia, Spain: ${ }^{7}$ Andalusian School of Public Health, Granada, Spain: ${ }^{8}$ Institute of Public Health, Navarra Cancer Registry, Pamplona, Spain: ${ }^{9}$ Department of Medicine, Surgery and Orthopaedics, Lund University, Malmö, Sweden: ${ }^{10}$ Department of Medical Biosciences, Pathology, Umeå University, Umeå, Sweden:

${ }^{11}$ Department of Public Health and Clinical Medicine, Nutrition Research, Umeå University, Umeå, Sweden:

${ }^{12}$ Medical Research Council Dunn Human Nutrition Unit, Cambridge, UK: ${ }^{13}$ University of Cambridge, Institute of Public Health, Strangeways Research Laboratory, Cambridge, UK: ${ }^{14}$ Cancer Research UK Epidemiology Unit, University of Oxford, Oxford, UK: ${ }^{15}$ Aarhus University, Department of Epidemiology and Social Medicine, Aarhus, Denmark: ${ }^{16}$ Danish Cancer Society, Institute of Cancer Epidemiology, Copenhagen, Denmark:

${ }^{17}$ INSERM, E3N-EPIC Group, Institute Gustave Roussy, Villejuif, France: ${ }^{18}$ German Institute of Human Nutrition, Department of Epidemiology, Potsdam-Rehbrücke, Germany: ${ }^{19}$ University of Athens Medical School, Department of Hygiene and Epidemiology, Athens, Greece: ${ }^{20}$ Coropi Health Center, Greek Ministry of Health, Athens, Greece: ${ }^{21}$ Epidemiology Unit, Italian National Cancer Institute, Milan, Italy: ${ }^{22}$ Molecular and Nutritional Epidemiology Unit, CSPO, Florence, Italy: ${ }^{23}$ Cancer Registry, Azienda Ospedaliera 'Civile MP Arezzo', Ragusa, Italy: ${ }^{24}$ University of Turin, Turin, Italy: ${ }^{25}$ Department of Clinical and Experimental Medicine, Federico II University, Naples, Italy: ${ }^{26}$ National Institute of Public Health and the Environment, Centre for Nutrition and Health, Bilthoven, The Netherlands: ${ }^{27}$ Julius Center for Health Sciences and Primary Care, University Medical Center, Utrecht, The Netherlands: ${ }^{28}$ Institute of Community Medicine, University of Tromsø, Tromsø, Norway

Submitted 21 December 2004: Accepted 10 August 2005

\footnotetext{
Abstract

Objective: There is increasing evidence for a significant effect of processed meat (PM) intake on cancer risk. However, refined knowledge on how components of this heterogeneous food group are associated with cancer risk is still missing. Here, actual data on the intake of PM subcategories is given; within a food-based approach we considered preservation methods, cooking methods and nutrient content for stratification, in order to address most of the aetiologically relevant hypotheses.

Design and setting: Standardised computerised 24-hour diet recall interviews were collected within the framework of the European Prospective Investigation into Cancer and Nutrition (EPIC), a prospective cohort study in 27 centres across 10 European countries.
} 
Subjects: Subjects were 22924 women and 13031 men aged 35-74 years.

Results: Except for the so-called 'health-conscious' cohort in the UK, energy-adjusted total PM intake ranged between 11.1 and $47.9 \mathrm{~g} \mathrm{day}^{-1}$ in women and 18.8 and $88.5 \mathrm{~g} \mathrm{day}^{-1}$ in men. Ham, salami-type sausages and heated sausages contributed most to the overall PM intake. The intake of cured (addition of nitrate/nitrite) PM was highest in the German, Dutch and northern European EPIC centres, with up to $68.8 \mathrm{~g}$ day $^{-1}$ in men. The same was true for smoked PM (up to $51.8 \mathrm{~g} \mathrm{day}^{-1}$ ). However, due to the different manufacturing practice, the highest average intake of $\mathrm{NaNO}_{2}$ through $\mathrm{PM}$ consumption was found for the Spanish centres $\left(5.4 \mathrm{mg} \mathrm{day}^{-1}\right.$ in men) as compared with German and British centres. Spanish centres also showed the highest intake of NaCl-rich types of PM; most cholesterol- and iron-rich PM was consumed in central and northern European centres. Possibly hazardous cooking methods were more often used for PM preparation in central and northern European centres.

Conclusions: We applied a food-based categorisation of PM that addresses aetiologically relevant mechanisms for cancer development and found distinct differences in dietary intake of these categories of PM across European cohorts. This predisposes EPIC to further investigate the role of PM in cancer aetiology.

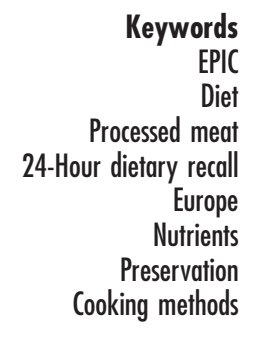

Several studies have already shown a positive association between meat consumption and different types of cancer, especially colorectal cancer ${ }^{1}$. In a recent review a higher risk of colorectal cancer was calculated for a high intake of processed meat (PM) and red meat; additionally, a strong dose-response relationship between $\mathrm{PM}$ intake and colorectal cancer risk (1.36, 95\% confidence interval $1.15-1.61$, for consumption of $30 \mathrm{~g} \mathrm{day}^{-1}$ vs. no consumption) existed ${ }^{2}$. An even stronger association was provided by a recent meta-analysis, where Sandhu et al. ${ }^{3}$ showed a significant $49 \%$ increased risk for a daily increase of $25 \mathrm{~g}$ of PM. In addition, associations between PM consumption and gastric cancer ${ }^{4-6}$, lung cancer $^{7}$, cancer of the upper aerodigestive tract ${ }^{8,9}$, prostate cancer ${ }^{10,11}$ and cancer of the lower urinary tract ${ }^{12}$ have been observed. There are also reports linking maternal intake of cured meat to the risk of brain tumours in childhood ${ }^{13,14}$

Several mechanisms have been hypothesised to explain associations between the consumption of PM and cancer risk; not all of them, however, are specific for PM. In general, it may be mediated through (1) an increased intake of (pre-)carcinogens or their precursors as well as (2) a high intake of specific nutrients enhancing the development of carcinogenic processes. Suggested mechanisms include the production of heterocyclic aromatic amines (HCA) during cooking ${ }^{15}$, an increased content of polycyclic aromatic hydrocarbons (PAH) by certain cooking and smoking methods applied to $\mathrm{PM}^{16}$, the presence of preformed $N$-nitroso compounds (NOC) from nitrates and nitrites added for preservation purposes, endogenous production of NOC by means of the high haem content in PM produced from red meat ${ }^{17}$, and the content of lipid (fatty acids, cholesterol) oxidation products arising during processing and storage ${ }^{18}$.

Concerning nutrient effects, curing increases drastically the originally low $\mathrm{NaCl}$ content of fresh meat and a high intake of salted food is associated with the risk of gastric cancer ${ }^{1}$. Further, high haem iron intake may be linked to carcinogenesis via enhancement of endogenous NOC production and oxidative damage to macromolecules, including lipids and $\mathrm{DNA}^{19}$. Therefore, also categorisation of PM by lipid content seems a promising approach. In particular, formation of cholesterol oxidation products during preparation and storage of PM has been described $^{18,20,21}$ and a link between $7 \beta$-hydroxycholesterol and lung cancer risk has been suggested ${ }^{22}$.

To the best of our knowledge, a systematic analysis of factors that might contribute to a higher cancer risk due to high PM consumption has not been conducted so far. The European Prospective Investigation into Cancer and Nutrition (EPIC) offers the opportunity to study the diversity of food and nutrition habits in Europe because detailed nutrition information on type and preparation of the consumed PM is available for a subset of EPIC participants. Therefore, the aim of the present work is to describe PM intake in categories which reflect suggested aetiological factors and mechanisms that might help to explain the association of PM intake and cancer risk. We applied a food-based approach considering preservation methods, cooking methods and nutrient content for stratification; the definition of the subgroups and categories that we were able to build is given in the following section. The results may be the basis for more refined aetiological analyses in EPIC to disentangle the different mechanistic hypotheses on the effect of PM.

\section{Material and methods Subjects}

The EPIC cohort study includes about half a million subjects from 10 European countries (France, Italy, Spain, Greece, The Netherlands, the United Kingdom, Germany, Denmark, Sweden, Norway) $)^{23}$. Information on the usual 
individual dietary intakes of all participants was assessed using different dietary questionnaires developed and validated in each participating country. In order to adjust (at the group level) for systematic measurement error between countries, highly standardised 24-hour recalls were performed in a sub-sample $(5-12 \%$ of the whole cohort) of each cohort as an additional dietary measurement ${ }^{23,24}$. Results presented in this paper are based on 24hour recalls from 35955 subjects (22924 women and 13031 men) participating in the EPIC calibration study between 1995 and 1998 (except Norway: 1999-2000). The age of the participants ranged from 35 to 74 years at recruitment. The distribution of study participants over the 27 study centres in 10 European countries is given in Table 1 . The initial 23 EPIC coordinating centres were redefined in France, the UK and Norway. In the UK, the 'health-conscious group' and the subjects recruited from the general population both in Cambridge and Oxford ('general population group') were considered as two separate population groups. In France and Norway, where the study subjects were scattered all over the country, four and two geographical regions were defined, respectively. In France, Norway, Utrecht/The Netherlands and Naples/Italy, women only were recruited. A detailed description of further characteristics of study participants is given elsewhere ${ }^{24}$.

\section{Dietary assessment}

A computerised 24-hour diet recall interview software, EPIC-SOFT, was developed as a calibration instrument by the International Agency for Research on Cancer in collaboration with all EPIC study centres ${ }^{25}$. The program was adapted for each participating country in terms of foods and recipes included. EPIC-SOFT provides a common structure and interview interface for an optimised standardisation of the dietary interview procedure within and between EPIC centres. According to common food groups and food subgroups, the countries generated a list of the single food items expected to be consumed by their participants. The open design allowed iterative update of the food item list. Furthermore, national data on the energy, fat, carbohydrate and alcohol contents of the food items were inserted to allow a rapid quality check of individual total energy and macronutrient intakes at the end of the interview while the subject was still present. In the current investigation these data are used to calculate energy intake (for adjustment).

The current report describes the intake of the EPICSOFT food subgroup 'processed meat', which is a subgroup of the group 'meat' (the remainder of the 'meat' group being classified as 'fresh meat'). The subgroup 'processed meat' encompasses all meat items that were further processed for preservation by salting (addition of $\mathrm{NaCl}$ ), curing (addition of $\mathrm{NaCl}$ containing nitrite or nitrate), smoking, marinating or cooking, or that have been bought as a ready-to-eat product (including those with an unknown recipe). The food items of the subgroup 'processed meat' were reclassified in different ways according to current hypotheses related to their preparation and preservation methods with the support from experts of each participating country.

The first classification scheme referred to the following groups, mainly with respect to the preparation and preservation method: raw (i.e. preserved but not cooked) ham, cooked ham, bacon, raw and spreadable sausage, salami-type sausage and heated sausage. Additionally, data for minced PM (such as hamburger, fricadel, meat balls) and PM cuts (e.g. 'schnitzel', slices of cold roasted meat, roasted meat in aspic) are given. In EPIC, minced meat and meat cuts were usually attached to fresh meat (mainly pork and beef; being part of a recipe); however, when bought as a ready-to-eat product it was attributed to the subgroup 'processed meat'.

Second, PM food items were aggregated using the preservation method: curing (i.e. addition of $\mathrm{NaCl}$ which contains nitrite/nitrate) and smoking. In countries for which analytical data on the nitrite/nitrate concentration in readyto-eat products were available (Germany, Spain, UK), mean nitrite/nitrate intake by PM consumption was calculated. For Germany, the analytical data gained between 1994 and 1998 by the Federal Institute of Meat Science, Kulmbach, were used; for the UK, data were taken from the MAFF UK Food Surveillance Info Sheet 142 (February 1998) providing analytical data for bacon and cured meat products collected in 1996/1997; for Spain, country-specific data were evaluated and average $\mathrm{NaNO}_{2}$ contents calculated with assistance from a national expert in meat science.

Third, PM was classified according to the nutrient concentration as rich in salt $(\mathrm{NaCl})$, haem and myoglobin iron (Fe), or cholesterol. For each country, single PM food items were listed by decreasing $\mathrm{NaCl}$, Fe or cholesterol content as provided by the national EPIC centres and based on national food composition data. As valid surrogates at the food level, raw ham plus salami-type sausages (NaCl-rich; > $3 \mathrm{~g} \mathrm{NaCl} / 100 \mathrm{~g}$ PM), liver-containing PM (cholesterol-rich; > $>0 \mathrm{mg}$ cholesterol/100 g) as well as blood- and liver-containing PM (haem and myoglobin Fe-rich; $>3$ mg Fe/100 g) were identified. The contribution of PM intake to dietary fat intake was given in an earlier report ${ }^{26}$ and was not further explored here.

Fourth, PM and PM subgroups were classified according to the application of cooking methods that can cause increased formation of the carcinogenic or potentially carcinogenic agents PAH and HCA. These so-called 'possibly hazardous cooking methods' (HCM) include barbecuing, frying and grilling. A detailed description of the use of cooking methods for the preparation of meat and fish was given elsewhere ${ }^{27}$.

Due to differences in the extent of mis-(under-)reporting between centres ${ }^{28}$, all results were adjusted for total energy intake (continuous variable). Furthermore, adjustment within centres or countries was performed to correct for deviations from an ideal sampling of the 24-hour recalls 
(weekday, season) as well as for age. For weekdays, two discrete levels (Monday-Friday; Saturday and Sunday) and for season four discrete levels were applied (weighting). Age was included as a continuous variable. The presentation of the results is stratified for sex and centre. Calculations were done by means of SPSS ${ }^{\circledR}$ for Windows ${ }^{\mathrm{TM}}$ Release 10.0.7 (SPSS Inc., Chicago, IL, USA) and SAS System ${ }^{\circledR}$ for Windows ${ }^{\mathrm{TM}}$ Release 8.00 (SAS Institute Inc., Cary, NC, USA).

\section{Results}

\section{Overall PM intake}

Adjusted mean total PM intake showed a high range of variation across EPIC (Tables $1 \mathrm{a}$ and 1b). Except for the 'health-conscious' cohort (a large proportion of whom were vegetarian) in the UK ( $4.9 \mathrm{~g} \mathrm{day}^{-1}$ in women, $13.4 \mathrm{~g}$ day $^{-1}$ in men), the lowest intake was found in Greece (11.1 and $18.8 \mathrm{~g} \mathrm{day}^{-1}$ in women and men, respectively) and the highest in north-western Norway (women, $47.9 \mathrm{~g}$ day $^{-1}$ ) and Potsdam/Germany (men, $88.5 \mathrm{~g} \mathrm{day}^{-1}$ ). Overall, heated sausages, ham (raw and cooked) and salami-type sausages contributed most to total PM intake.

\section{PM intake by preservation metbod}

With respect to PM products that have not been cooked ('raw'), i.e. raw ham, raw and spreadable sausages and salami-type sausages, the consumption of raw ham and salami-type sausages was highest in the Spanish centres (Tables 1a and 1b). Considerable amounts of raw and spreadable sausages were consumed in the UK cohort (general population). Heated sausages were the preferably consumed types of PM in the cohorts of The Netherlands, Germany and the Nordic countries (Denmark, Sweden and Norway).

Most raw PM has been cured, i.e. preserved by means of addition of salt $(\mathrm{NaCl})$ containing nitrate and/or nitrite. However, cooked sausages were often cured as well. In general, the intake of cured PM is higher in the EPIC cohorts of central and northern Europe than in the southern cohorts (Tables $2 \mathrm{a}$ and 2b). Smoking of PM was more often applied in central and northern countries than in the French, Italian or Spanish centres. Almost all smoked PM has been cured as well.

$\mathrm{NaNO}_{2}$ intake by PM consumption was estimated for three EPIC countries for which analytical data were available. The mean $\mathrm{NaNO}_{2}$ intake varied between 0.1 and $3.3 \mathrm{mg} \mathrm{day}^{-1}$ in women and 0.8 and $5.4 \mathrm{mg} \mathrm{day}^{-1}$ in men in the different centres (Table 3). The highest intake was calculated for the Spanish EPIC cohorts, whereas the intake was considerably lower in the German as well as the British cohorts.

\section{PM intake by nutrient content}

Salting, i.e. addition of $\mathrm{NaCl}$, is a common preservation method and PM can be categorised according to $\mathrm{NaCl}$ content. The consumption of NaCl-rich PM (raw ham and salami-type sausages) was found to be highest in the Spanish centres $\left(>20 \mathrm{~g} \mathrm{day}^{-1}\right.$ among men, $>10 \mathrm{~g} \mathrm{day}^{-1}$ among women), followed by the North Italian centres of Florence, Varese and Turin, while it was lowest in the British cohorts (Tables $4 \mathrm{a}$ and $4 \mathrm{~b}$ ).

The intake of haem and myoglobin iron-rich PM is reflected by the extent of consumption of liver- and blood-containing PM. The intake was highest in Danish and Swedish centres (Tables $4 \mathrm{a}$ and $4 \mathrm{~b}$ ). Considering only blood-containing PM, the Spanish centres of Granada (men, $7.3 \mathrm{~g} \mathrm{day}^{-1}$ ) and San Sebastian (women, $3.7 \mathrm{~g} \mathrm{day}^{-1}$ ) showed the highest consumption level.

Liver-containing PM has the highest cholesterol content among the PM food items. Men in the Danish cohorts consumed on average $>10 \mathrm{~g}$ of livercontaining PM daily, followed by Malmö/Sweden and Potsdam/Germany. At the low end, liver-containing PM was rarely consumed in the Italian and Spanish centres (Tables $4 \mathrm{a}$ and $4 \mathrm{~b}$ ).

\section{PM intake by cooking method}

PM was cooked differently in the EPIC centres and, with few exceptions, HCM (frying, grilling, barbecuing) were more often used in northern and central European than in the southern EPIC centres (Tables $5 \mathrm{a}$ and 5b). While barbecued and grilled PM were consumed rarely, fried PM contributed most to the consumption. However, in the UK, the French centres and some Italian centres, grilling is the most frequently used HCM. PM most often prepared by these three cooking methods was bacon and ham, minced PM and sausages. Especially in the centres of central and northern Europe sausages contributed most to the total consumption of PM prepared by HCM. PM that was cured and prepared by HCM was consumed in higher amounts in Navarra/Spain (women: $12.0 \mathrm{~g} \mathrm{day}^{-1}$; men: $16.1 \mathrm{~g} \mathrm{day}^{-1}$ ) as well as in the Swedish and Norwegian centres. In these centres, the intake of cured and smoked PM cooked by the three high-temperature methods was high as well.

\section{Discussion}

To the best of our knowledge this is the first report that describes systematically the consumption of different types of PM and its characteristics in Europe by several factors that might be potential risk factors for different types of cancer when larger amounts of PM - mostly from red meat - are consumed. The results of this study clearly show the diversity and heterogeneity that exist within the EPIC cohorts.

Due to the lack of similar studies, comparisons of our results, as assessed by means of a 24 -hour recall in a 
Consumption of types and characteristics of processed meat in EPIC

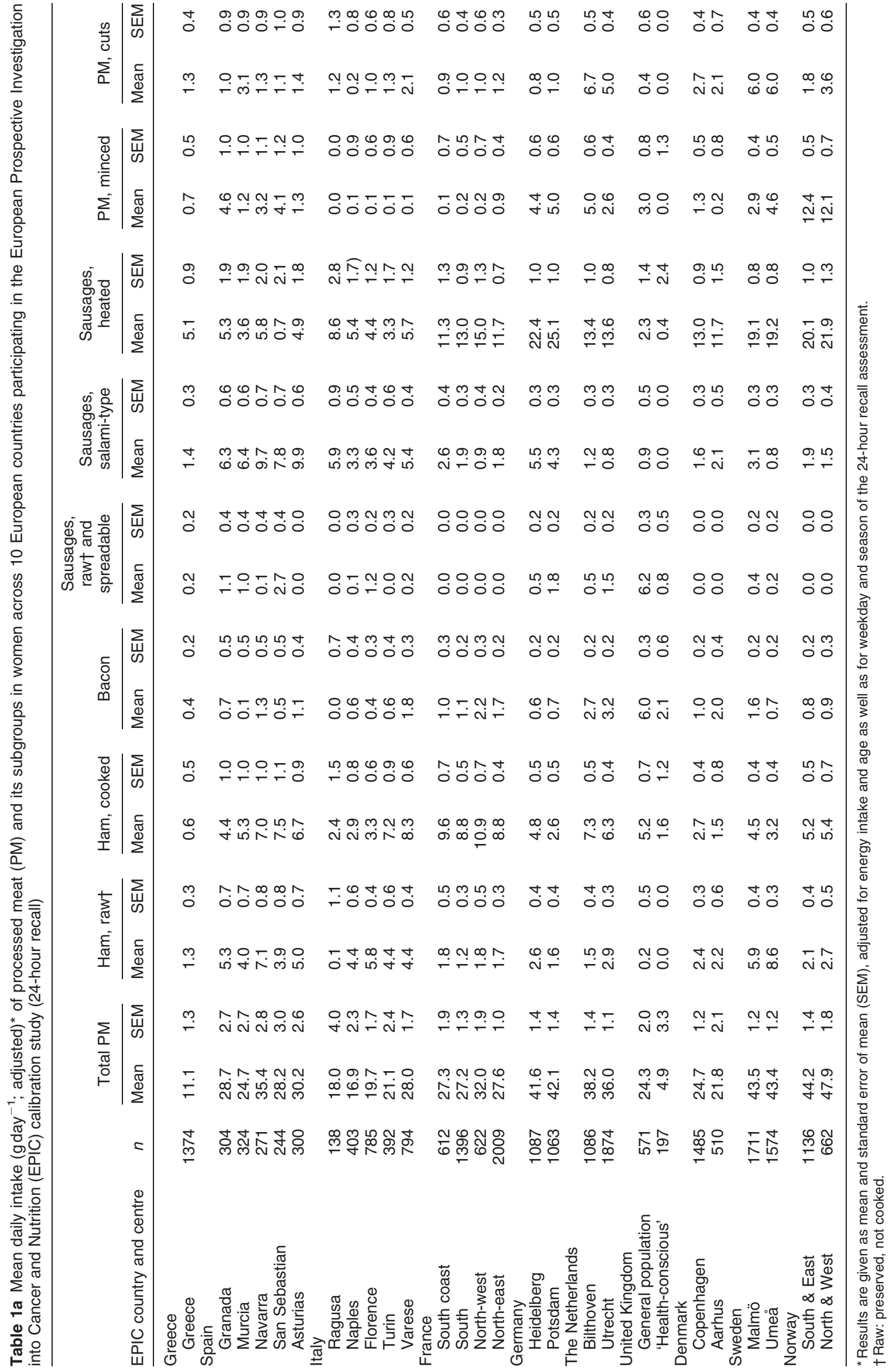


Consumption of types and characteristics of processed meat in EPIC

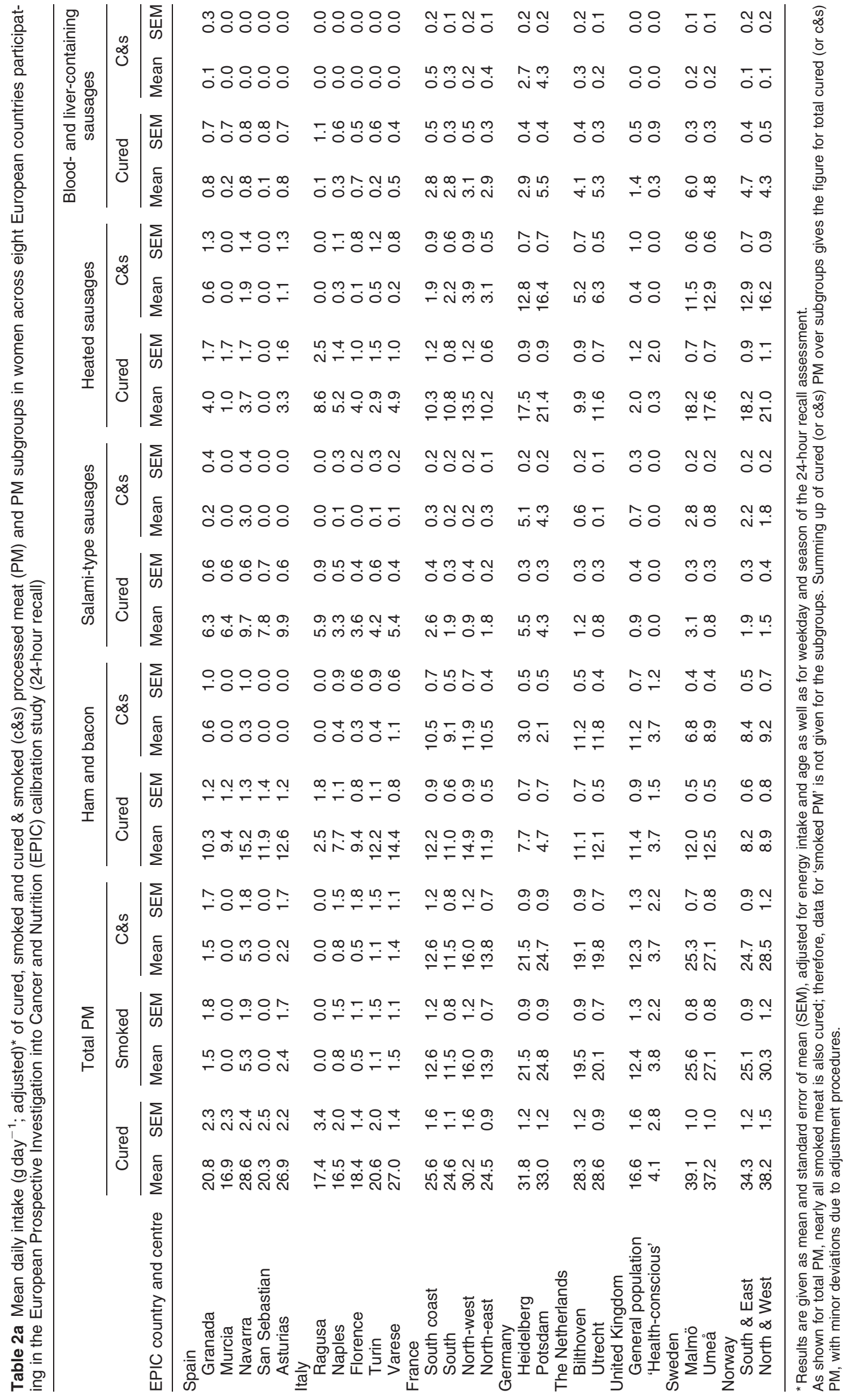


Table 3 Mean daily intake of nitrite/nitrate (calculated as $\mathrm{mg}$ $\mathrm{NaNO}_{2}$ per day, adjusted ${ }^{*}$ ) by consumption of processed meat in women and men from European Prospective Investigation into Cancer and Nutrition (EPIC) centres in Spain, Germany and the United Kingdom (24-hour recalls)

\begin{tabular}{llll}
\hline & \multicolumn{3}{c}{$\mathrm{NaNO}_{2}$ intake $\left(\mathrm{mg} \mathrm{day}^{-1}\right)$} \\
\cline { 2 - 4 } EPIC country and centre & Mean & SEM & $95 \% \mathrm{Cl}$ \\
\hline Women & & & \\
Spain & & & \\
$\quad$ Granada & 2.35 & 0.17 & $2.03-2.67$ \\
$\quad$ Murcia & 1.97 & 0.16 & $1.65-2.29$ \\
$\quad$ Navarra & 3.35 & 0.17 & $3.01-3.69$ \\
$\quad$ San Sebastian & 2.59 & 0.18 & $2.23-2.95$ \\
$\quad$ Asturias & 3.26 & 0.16 & $2.94-3.57$ \\
Germany & & & \\
$\quad$ Heidelberg & 1.35 & 0.09 & $1.18-1.52$ \\
$\quad$ Potsdam & 1.39 & 0.09 & $1.22-1.56$ \\
United Kingdom & & & \\
$\quad$ General population & 0.63 & 0.12 & $0.39-0.86$ \\
$\quad$ 'Health-conscious' & 0.10 & 0.20 & $0.00-0.50$ \\
Men & & & \\
Spain & & & \\
$\quad$ Granada & 3.85 & 0.31 & $3.24-4.47$ \\
$\quad$ Murcia & 3.20 & 0.29 & $2.63-3.77$ \\
$\quad$ Navarra & 5.17 & 0.22 & $4.75-5.60$ \\
$\quad$ San Sebastian & 4.62 & 0.21 & $4.20-5.03$ \\
$\quad$ Asturias & 5.44 & 0.23 & $4.98-5.89$ \\
Germany & & & \\
$\quad$ Heidelberg & 2.82 & 0.14 & $2.54-3.10$ \\
$\quad$ Potsdam & 3.13 & 0.13 & $2.88-3.39$ \\
United Kingdom & & & \\
$\quad$ General population & 1.08 & 0.23 & $0.64-1.53$ \\
$\quad$ 'Health-conscious' & 0.76 & 0.43 & $0.00-1.60$ \\
\hline
\end{tabular}

SEM - standard error of mean; $\mathrm{Cl}$ - confidence interval.

* Adjusted for energy intake, age, weekday and season of the 24-hour recall assessment.

sub-population of each cohort, with the situation in the underlying populations are limited. However, a fairly good agreement with the results of studies that assessed meat and PM consumption in selected European regions and countries was noted in an earlier report on meat consumption in EPIC using the same database ${ }^{26}$. Valid and comparable dietary data with focus on the intake of different types of PM are, however, rare. Most data derive from food-frequency questionnaires used to study the association between food intake and cancer risk; these data are suitable for categorisation of individuals but do not necessarily give the actual intake level and provide sufficient details on the specific types of PM.

Differences in under- or overreporting among the study regions might influence the quality of our results ${ }^{28}$. Meat intake is affected by underreporting in EPIC Greece and southern Spain ${ }^{26}$. To keep the effect of misreporting as small as possible, all analysed data were adjusted for total energy intake. An effect of seasonal variation on food consumption in the EPIC calibration study ${ }^{24}$ seems likely to affect the intake of special types and characteristics of $\mathrm{PM}$ as well, e.g. the use of cooking methods like barbecuing or grilling. This aspect has been taken into account by adjusting for season as well as for weekday of the 24-hour recalls.
A number of mechanisms have been proposed as the means by which high intakes of PM may increase the risk of cancer. Humans are exposed to NOC, including nitrosamines, both from the diet (and other environmental sources) and from endogenous synthesis ${ }^{29}$. Preformed NOC in foods have been found almost exclusively in foods containing nitrite or which were exposed to nitrogen oxides. Thus, cured meat and meat products might be the most important contributors to dietary preformed NOC. Additionally, smoking or direct-fire drying increases the NOC concentration in food ${ }^{2,29}$. Haorah et al. ${ }^{30}$ have shown that the concentration of NOC and their precursors varies widely in foods and even in the same product that was purchased at different times, making it difficult to reliably estimate dietary intake. In addition to this exogenous exposure, there is extensive endogenous nitrate and nitrite generation from inducible and endogenous NO synthases and resulting NOC production in the body. NOC arise from the reaction of nitrite and secondary or tertiary amines in the intestine from $N$-nitrosation of amines which in the colon can be produced by bacterial decarboxylation of amino acids ${ }^{31}$. Bingham et al. ${ }^{31}$ have shown that haem in red (fresh and processed) but not white meat substantially increases the endogenous burden of NOC. Excess nitrate can also increase endogenous NOC production ${ }^{32}$.

The intake of the NOC precursor nitrite as well as the consumption of cured meat were positively associated with cancer risk of the prostate ${ }^{10}$ and lower urinary tract ${ }^{12}$. Associations of nitrite, cured meat or NOC intake with gastric cancer are inconsistent ${ }^{4-6}$. Penttila et al. ${ }^{33}$ estimated that the intake of cured meat products contributes $97 \%$ of the total dietary nitrite intake in Finland. In the current investigation, total intake of cured PM is lower in the Mediterranean EPIC centres than in the central and northern European centres. In contrast, the estimated intake of nitrate/nitrite by PM consumption, calculated as $\mathrm{NaNO}_{2}$, is higher in Spanish EPIC cohorts than in the UK and Germany. Although upper limits for the $\mathrm{NaNO}_{2}$ concentration in meat products exist in most European countries, valid data on $\mathrm{NaNO}_{2}$ concentration in ready-toeat products for intake calculations were available only in these three EPIC countries. The results clearly show marked differences in the amount of nitrite/nitrate added for the production of cured PM as well as differences in factors modulating the formation of nitrite in preserved PM during storage and ripening ${ }^{14}$. In Spain, where salami-type sausages and ham form the majority of intake of cured meat, the amount of nitrate/nitrite added for preservation and probably storage conditions might differ from other countries. Furthermore, the content of additives in food changes over time ${ }^{34}$. Developments in manufacturing practice during the last decades, e.g. addition of ascorbic acid, decreased the amount of nitrate/nitrite added to PM products in most European countries ${ }^{35}$. This raises the question whether information at the food level as an indicator of cured PM consumption is sufficient to describe 
Table 4a Mean daily intake ( $\mathrm{g} \mathrm{day}^{-1}$; adjusted)* of processed meat (PM) subgroups as classified according to their cholesterol, iron or salt content in women across 10 European countries participating in the European Prospective Investigation into Cancer and Nutrition (EPIC) calibration study (24-hour recall)

\begin{tabular}{|c|c|c|c|c|c|c|c|c|}
\hline \multirow[b]{3}{*}{ EPIC country and centre } & \multirow{2}{*}{\multicolumn{2}{|c|}{$\begin{array}{l}\text { Cholesterol-rich } \\
\text { Liver-containing } \\
\text { PM }\end{array}$}} & \multicolumn{4}{|c|}{ Fe-rich } & \multirow{2}{*}{\multicolumn{2}{|c|}{ 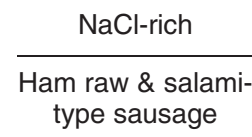 }} \\
\hline & & & \multicolumn{2}{|c|}{$\begin{array}{c}\text { Blood-containing } \\
\text { PM }\end{array}$} & \multicolumn{2}{|c|}{$\begin{array}{l}\text { Blood- and liver- } \\
\text { containing PM }\end{array}$} & & \\
\hline & Mean & SEM & Mean & SEM & Mean & SEM & Mean & SEM \\
\hline \multicolumn{9}{|l|}{ Greece } \\
\hline Greece & - & - & - & - & - & - & 2.7 & 0.5 \\
\hline \multicolumn{9}{|l|}{ Spain } \\
\hline Granada & 0.8 & 0.8 & 1.4 & 0.5 & 2.2 & 1.0 & 11.6 & 1.0 \\
\hline Murcia & 0.1 & 0.8 & 1.0 & 0.5 & 1.2 & 0.9 & 10.4 & 1.0 \\
\hline Navarra & 0.8 & 0.8 & 1.4 & 0.6 & 2.2 & 1.0 & 16.9 & 1.0 \\
\hline San Sebastian & 0.0 & 0.9 & 3.7 & 0.6 & 3.7 & 1.1 & 11.7 & 1.1 \\
\hline Asturias & 0.8 & 0.8 & 1.1 & 0.5 & 1.9 & 0.9 & 14.8 & 0.9 \\
\hline \multicolumn{9}{|l|}{ Italy } \\
\hline Ragusa & 0.1 & 1.2 & 0.0 & 0.0 & 0.1 & 1.4 & 6.0 & 1.4 \\
\hline Naples & 0.3 & 0.7 & 0.1 & 0.5 & 0.4 & 0.8 & 7.6 & 0.8 \\
\hline Florence & 1.2 & 0.5 & 0.1 & 0.3 & 1.3 & 0.6 & 9.4 & 0.6 \\
\hline Turin & 0.2 & 0.7 & 0.0 & 0.5 & 0.3 & 0.8 & 8.6 & 0.8 \\
\hline Varese & 0.5 & 0.5 & 0.0 & 0.3 & 0.5 & 0.6 & 9.8 & 0.6 \\
\hline \multicolumn{9}{|l|}{ France } \\
\hline South coast & 2.5 & 0.6 & 1.3 & 0.4 & 3.8 & 0.7 & 4.4 & 0.7 \\
\hline South & 3.5 & 0.4 & 1.3 & 0.2 & 4.7 & 0.4 & 3.2 & 0.4 \\
\hline North-west & 3.0 & 0.5 & 1.1 & 0.4 & 4.1 & 0.7 & 2.7 & 0.7 \\
\hline North-east & 3.7 & 0.3 & 1.1 & 0.2 & 4.8 & 0.4 & 3.4 & 0.4 \\
\hline \multicolumn{9}{|l|}{ Germany } \\
\hline Heidelberg & 2.8 & 0.4 & 0.4 & 0.3 & 3.2 & 0.5 & 8.0 & 0.5 \\
\hline Potsdam & 4.1 & 0.4 & 1.4 & 0.3 & 5.5 & 0.5 & 5.9 & 0.5 \\
\hline \multicolumn{9}{|l|}{ The Netherlands } \\
\hline Bilthoven & 3.8 & 0.4 & 0.1 & 0.3 & 3.9 & 0.5 & 2.6 & 0.5 \\
\hline Utrecht & 4.6 & 0.3 & 0.7 & 0.2 & 5.3 & 0.4 & 3.7 & 0.4 \\
\hline \multicolumn{9}{|l|}{ United Kingdom } \\
\hline General population & 1.4 & 0.6 & 0.1 & 0.4 & 1.5 & 0.7 & 1.1 & 0.7 \\
\hline 'Health-conscious' & 0.3 & 1.0 & 0.0 & 0.0 & 0.3 & 1.2 & 0.0 & 0.0 \\
\hline \multicolumn{9}{|l|}{ Denmark } \\
\hline Copenhagen & 4.6 & 0.4 & 1.1 & 0.2 & 5.7 & 0.4 & 3.9 & 0.4 \\
\hline Aarhus & 4.7 & 0.6 & 0.1 & 0.4 & 4.8 & 0.7 & 4.3 & 0.7 \\
\hline \multicolumn{9}{|l|}{ Sweden } \\
\hline Malmö & 5.8 & 0.3 & 1.1 & 0.2 & 6.9 & 0.4 & 9.0 & 0.4 \\
\hline Umeå & 4.5 & 0.3 & 1.8 & 0.2 & 6.4 & 0.4 & 9.4 & 0.4 \\
\hline \multicolumn{9}{|l|}{ Norway } \\
\hline South \& East & 4.6 & 0.4 & 0.2 & 0.3 & 4.8 & 0.5 & 4.0 & 0.5 \\
\hline North \& West & 4.2 & 0.5 & 0.3 & 0.4 & 4.6 & 0.6 & 4.2 & 0.7 \\
\hline
\end{tabular}

${ }^{*}$ Results are given as mean and standard error of mean (SEM), adjusted for energy intake and age as well as for weekday and season of the 24-hour recall assessment.

exposure differences for nitrite/nitrate through $\mathrm{PM}$ consumption, because this approach assumes a similar $\mathrm{NaNO}_{2}$ content in the ready-to-eat PM products in the different countries which might not be correct.

In a Finnish study, conducted between 1966 and 1972, mean intake of nitrite was $5.3 \mathrm{mg} \mathrm{day}^{-1}$, provided nearly exclusively by cured meats and $\mathrm{PM}^{5,36}$. However, another report from Finland calculated an average daily intake of $1.88 \mathrm{mg}^{33}$. In the UK, a daily nitrite intake of $2.4-4.2 \mathrm{mg}$ has been reported ${ }^{37}$, which is higher than estimated for the British EPIC cohort. In an Italian case-control study the mean daily nitrite intake was $3.5 \mathrm{mg}^{6}$. Using duplicate $24-$ hour diet samples, a median daily nitrite intake of $0.1 \mathrm{mg}$ with a range of $<0.1-16 \mathrm{mg}$ was found in a small Dutch sample $^{38}$. Comparing analytical data with intake data derived from calculations based on dietary intake estimations, the results obtained in a Polish study showed a limited deviation with 1.67 (analytical) versus 1.18 (calculated) $\mathrm{mg}$ nitrite per day and person ${ }^{39}$.

The incidence of stomach cancer is higher in the south than in the west and the north of Europe ${ }^{40}$. Evidence suggests that risk of stomach cancer is increased by high intake of some traditionally preserved salted foods, especially meats and pickles, and with salt per $s e^{1,41}$. Sodium chloride used for salting/curing enhances substantially the generally low $\mathrm{NaCl}$ concentration of fresh meat. Whether the intake of $\mathrm{NaCl}$ and PM-derived $\mathrm{NaCl}$ - the latter being highest in the Spanish EPIC centres, followed by Italian and Dutch centres - is a risk factor for stomach cancer in EPIC has to be examined in forthcoming risk evaluations.

Meat is smoked because of its inactivating effect on enzymes and micro-organisms as well as its effect on taste $^{42}$. However, smoke contains PAH formed by pyrolytic 
Table 4b Mean daily intake ( $\mathrm{gday}^{-1}$; adjusted) ${ }^{*}$ of processed meat (PM) subgroups as classified according to their cholesterol, iron or salt content in men across eight European countries participating in the European Prospective Investigation into Cancer and Nutrition (EPIC) calibration study (24-hour recall)

\begin{tabular}{|c|c|c|c|c|c|c|c|c|}
\hline \multirow[b]{3}{*}{ EPIC country and centre } & \multirow{2}{*}{\multicolumn{2}{|c|}{ 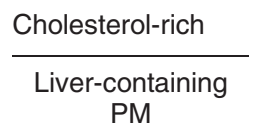 }} & \multicolumn{4}{|c|}{ Fe-rich } & \multirow{2}{*}{\multicolumn{2}{|c|}{ 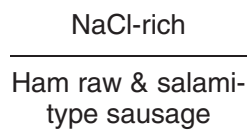 }} \\
\hline & & & \multicolumn{2}{|c|}{$\begin{array}{l}\text { Blood-containing } \\
\text { PM }\end{array}$} & \multicolumn{2}{|c|}{$\begin{array}{l}\text { Blood- and liver- } \\
\text { containing PM }\end{array}$} & & \\
\hline & Mean & SEM & Mean & SEM & Mean & SEM & Mean & SEM \\
\hline \multicolumn{9}{|l|}{ Greece } \\
\hline Greece & - & - & - & - & - & - & 4.6 & 0.8 \\
\hline \multicolumn{9}{|l|}{ Spain } \\
\hline Granada & 2.5 & 1.3 & 7.3 & 1.2 & 9.8 & 1.8 & 25.4 & 1.9 \\
\hline Murcia & 0.1 & 1.2 & 3.0 & 1.1 & 3.1 & 1.7 & 20.6 & 1.7 \\
\hline Navarra & 0.6 & 0.9 & 2.9 & 0.8 & 3.5 & 1.2 & 31.4 & 1.3 \\
\hline San Sebastian & 0.0 & 0.0 & 2.4 & 0.8 & 2.1 & 1.2 & 25.8 & 1.2 \\
\hline Asturias & 0.0 & 0.0 & 3.8 & 0.9 & 3.7 & 1.3 & 28.0 & 1.4 \\
\hline \multicolumn{9}{|l|}{ Italy } \\
\hline Ragusa & 0.0 & 0.0 & 0.0 & 0.0 & 0.0 & 0.0 & 8.7 & 2.1 \\
\hline Florence & 1.9 & 1.1 & 0.0 & 0.0 & 1.8 & 1.6 & 15.7 & 1.6 \\
\hline Turin & 0.3 & 0.7 & 0.1 & 0.7 & 0.4 & 1.0 & 14.9 & 1.0 \\
\hline Varese & 0.0 & 0.0 & 1.5 & 0.9 & 1.1 & 1.4 & 15.4 & 1.5 \\
\hline \multicolumn{9}{|l|}{ Germany } \\
\hline Heidelberg & 5.6 & 0.6 & 3.2 & 0.5 & 8.8 & 0.8 & 15.2 & 0.8 \\
\hline Potsdam & 9.1 & 0.5 & 3.1 & 0.5 & 12.2 & 0.7 & 16.7 & 0.8 \\
\hline \multicolumn{9}{|l|}{ The Netherlands } \\
\hline Bilthoven & 6.6 & 0.6 & 1.0 & 0.6 & 7.5 & 0.8 & 6.3 & 0.9 \\
\hline \multicolumn{9}{|l|}{ United Kingdom } \\
\hline General population & 2.3 & 0.9 & 0.8 & 0.8 & 3.0 & 1.3 & 1.3 & 1.3 \\
\hline 'Health-conscious' & 0.7 & 1.8 & 0.4 & 1.6 & 1.1 & 2.4 & 1.5 & 2.5 \\
\hline \multicolumn{9}{|l|}{ Denmark } \\
\hline Copenhagen & 14.8 & 0.5 & 2.6 & 0.5 & 17.4 & 0.7 & 7.1 & 0.7 \\
\hline Aarhus & 12.4 & 0.8 & 1.0 & 0.7 & 13.5 & 1.1 & 6.7 & 1.1 \\
\hline \multicolumn{9}{|l|}{ Sweden } \\
\hline Malmö & 9.8 & 0.5 & 1.2 & 0.5 & 11.0 & 0.7 & 14.9 & 0.8 \\
\hline Umeå & 6.2 & 0.5 & 4.4 & 0.5 & 10.6 & 0.7 & 9.2 & 0.7 \\
\hline
\end{tabular}

${ }^{*}$ Results are given as mean and standard error of mean (SEM), adjusted for energy intake and age as well as for weekday and season of the 24-hour recall assessment

processes at high smoking temperatures $\left(400-1000^{\circ} \mathrm{C}\right)$. The amount of PAH may vary widely depending greatly on the temperature, the type of wood used, the type of smoking (i.e. direct or indirect, hot or cold) and the use of smoke flavour additives ${ }^{42}$. Lung $^{43}$, pancreatic ${ }^{44}$ and gastric cancer ${ }^{45}$ were positively associated with the consumption of smoked meat. The differences in smoked PM intake described in this study would enable valid risk estimation in EPIC. However, two important limitations have to be kept in mind for such analyses. First, a broad variation in $\mathrm{PAH}$ concentration of smoked PM products is to be expected even within a country and for the same product. Second, almost all smoked PM has also been cured. However, the practice of smoking of PM is more prevalent in middle and northern Europe than in the south of Europe, allowing distinguishing between curing and smoking effects and possible interaction between both.

Associations between meat cooking and colon cancer $^{46,47}$, lung cancer $^{7,48}$, breast cancer ${ }^{49,50}$, stomach cancer $^{51}$ and prostate cancer ${ }^{52}$ were seen. The production of HCA during cooking at high temperatures or PAH during grilling and barbecuing is suspected to be responsible for the carcinogenic effect ${ }^{15,16}$. Accordingly, positive associations between the estimated HCA intake and cancer risk of different sites have been found in some studies but not in others ${ }^{47,49,52-56}$.

Interactions between HCM and smoking and curing of meat might further alter cancer risk. For example, carcinogens like benzo $(a)$ pyrene arise from grilling over wood or charcoal as well as from smoking. Consequently, grilling smoked sausage could lead to a higher PAH intake than grilling non-smoked sausages. Additionally, the mutagenic activity of broiled meat and fish treated with nitrite is higher than that of broiled meat and fish without nitrite treatment ${ }^{57}$. Frying cured PM, especially bacon, increases the NOC concentration in food ${ }^{29}$.

Iron may be associated with increased risk of colorectal cancer via several mechanisms. Haem iron from red meat and thus most PM is associated with increased endogenous NOC formation ${ }^{17}$. In vitro data support the hypothesis that inorganic iron in the gut is a risk factor during human carcinogenesis by enhancing oxidative genetic damage in human colon cells ${ }^{19}$. Deneo-Pellegrini et al. ${ }^{58}$ observed a higher risk of rectal tumours in a case-control study in Uruguay with increasing intake of dietary iron even after adjusting for meat intake. The risk of tumours of the proximal colon was associated with an increasing intake of dietary iron in two US studies ${ }^{59,60}$. Blood- and 


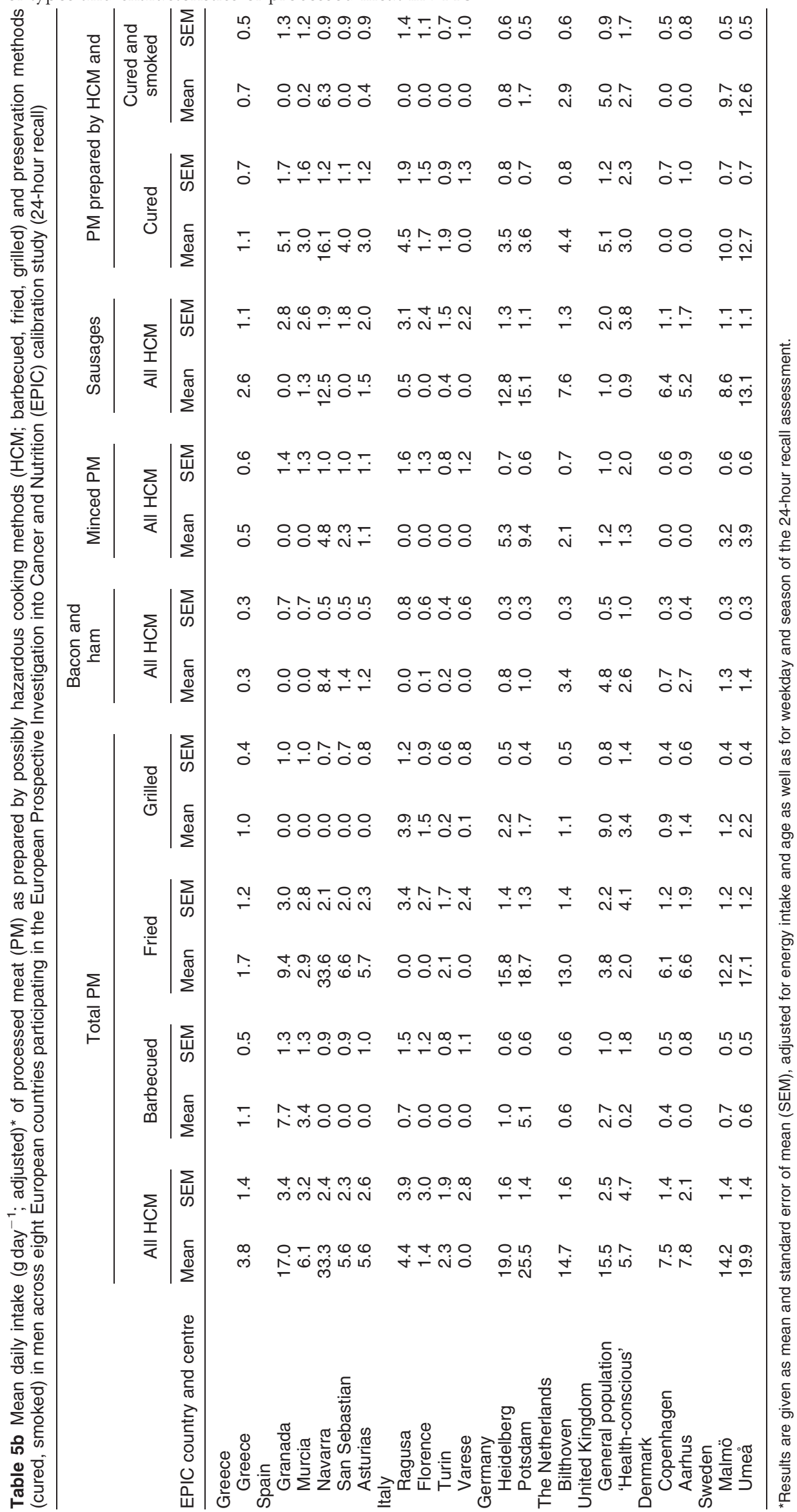


liver-containing PM are rich in iron and seem to be an important source of dietary iron intake at least in some centres of middle and northern Europe (Tables $4 \mathrm{a}$ and $4 \mathrm{~b}$ ). Iron may also act as a potent oxidant in foods themselves by forming lipid oxidation products that are absorbed in the human gut ${ }^{61}$. Kato et al. ${ }^{59}$ noticed a significantly higher risk among subjects with a high fat as well as a high iron intake.

It is known that cholesterol oxidation products are formed during preparation and storage of PM in various amounts $^{18,20,21}$ and although a meta-analysis of prospective studies concluded that dietary cholesterol does not significantly contribute to lung cancer risk $^{62}$, in a recent nested case-control study plasma $7 \beta$-hydroxycholesterol concentrations before onset of disease were significantly associated with lung cancer risk $^{22}$. The plasma concentration of $7 \beta$-hydroxycholesterol increased significantly the more meat, including PM, was consumed. Cholesterol oxidation products, rather than cholesterol, in PM may be important in cancer risk ${ }^{63}$.

The higher consumption of PM in the cohorts of north and central Europe coincides with higher rates of colorectal cancers in these countries, while rates are considerably lower in southern European countries ${ }^{40}$. This would fit with the results of recent meta-analyses showing that PM consumption is positively associated with colorectal cancer risk ${ }^{2,3}$. The search for causal factors behind this association is, however, an enormous challenge. Although biological explanations are provided for several aspects of PM intake, prospective epidemiological studies are needed to confirm these hypotheses. EPIC offers the opportunity to investigate these questions in a study setting with a large sample size combined with strongly varying dietary habits in between the south and the north of Europe. Calibration of the country-specific dietary questionnaires used in EPIC by means of data shown here using detailed 24-hour recalls will be of important added benefit in investigating the relationship between PM and cancer incidence.

\section{Acknowledgements}

We wish to thank all study participants for their cooperation and all the interviewers who participated in the fieldwork studies in each EPIC centre. In addition, the assistance of national experts in meat science and technology to categorise different PM items according to the usual practice of production is kindly acknowledged.

The work described in the paper was carried out with the financial support of the 'Europe Against Cancer' Programme of the European Commission (SANCO); Ligue contre le Cancer (France); Société 3M (France); Mutuelle Générale de l'Education Nationale; Institut National de la Santé et de la Recherche Médicale (INSERM); Institut Gustave Roussy; German Cancer Aid; German Cancer Research Center; German Federal Ministry of Education and Research; Danish Cancer Society; Health Research Fund (FIS) of the Spanish Ministry of Health; the Spanish Regional Governments of Andalucia, Asturia, Basque Country, Murcia and Navarra; Cancer Research UK; Medical Research Council, UK; the Stroke Association, UK; British Heart Foundation; Department of Health, UK; Food Standards Agency, UK; the Wellcome Trust, UK; Greek Ministry of Health; Greek Ministry of Education; Italian Association for Research on Cancer; Italian National Research Council; Dutch Ministry of Public Health, Welfare and Sports; Dutch Prevention Funds; LK Research Funds; Dutch ZON (Zorg Onderzoek Nederland); World Cancer Research Fund; Swedish Cancer Society; Swedish Scientific Council; Regional Government of Skane, Sweden; Norwegian Cancer Society; the Norwegian Research Council.

\section{References}

1 World Cancer Research Fund (WCRF)/American Institute for Cancer Research (AICR). Food, Nutrition and the Prevention of Cancer: A Global Perspective. Washington, DC: WCRF/AICR, 1997.

2 Norat T, Lukanova A, Ferrari P, Riboli E. Meat consumption and colorectal cancer risk: dose-response meta-analysis of epidemiological studies. International Journal of Cancer 2002; 98(2): 241-56.

3 Sandhu MS, White IR, McPherson K. Systematic review of the prospective cohort studies on meat consumption and colorectal cancer risk: a meta-analytical approach. Cancer Epidemiology, Biomarkers \& Prevention 2001; 10(5): 439-46.

4 Ngoan LT, Mizoue T, Fujino Y, Tokui N, Yoshimura T. Dietary factors and stomach cancer mortality. British Journal of Cancer 2002; 87(1): 37-42.

5 Knekt P, Jarvinen R, Dich J, Hakulinen T. Risk of colorectal and other gastro-intestinal cancers after exposure to nitrate, nitrite and $N$-nitroso compounds: a follow-up study. International Journal of Cancer 1999; 80(6): 852-6.

6 Palli D, Russo A, Ottini L, Masala G, Saieva C, Amorosi A, et al. Red meat, family history, and increased risk of gastric cancer with microsatellite instability. Cancer Research 2001; 61(14): 5415-9.

7 Deneo-Pellegrini H, De Stefani E, Ronco A, Mendilaharsu M, Carzoglio JC. Meat consumption and risk of lung cancer; a case-control study from Uruguay. Lung Cancer 1996; 14(2-3): 195-205.

8 Bosetti C, La Vecchia C, Talamini R, Negri E, Levi F, Dal Maso $\mathrm{L}$, et al. Food groups and laryngeal cancer risk: a casecontrol study from Italy and Switzerland. International Journal of Cancer 2002; 100(3): 355-60.

9 Levi F, Pasche C, Lucchini F, Franceschi S, Monnier P, La Vecchia C. Food groups and oesophageal cancer risk in Vaud, Switzerland. European Journal of Cancer Prevention 2000; 9(4): 257-63.

10 Schuurman AG, van den Brandt PA, Dorant E, Goldbohm RA. Animal products, calcium and protein and prostate cancer risk in The Netherlands Cohort Study. British Journal of Cancer 1999; 80(7): 1107-13.

11 Michaud DS, Augustsson K, Rimm EB, Stampfer MJ, Willett WC, Giovannucci E. A prospective study on intake of animal products and risk of prostate cancer. Cancer Causes $\mathcal{E}$ Control 2001; 12(6): 557-67.

12 Wilkens LR, Kadir MM, Kolonel LN, Nomura AM, Hankin JH. Risk factors for lower urinary tract cancer: the role of total 
fluid consumption, nitrites and nitrosamines, and selected foods. Cancer Epidemiology, Biomarkers \& Prevention 1996; 5(3): 161-6.

13 Blot WJ, Henderson BE, Boice JD Jr. Childhood cancer in relation to cured meat intake: review of the epidemiological evidence. Nutrition and Cancer 1999; 34(1): 111-8.

14 Pogoda JM, Preston-Martin S. Maternal cured meat consumption during pregnancy and risk of paediatric brain tumour in offspring: potentially harmful levels of intake. Public Health Nutrition 2001; 4(2): 183-9.

15 Skog KI, Johansson MA, Jagerstad MI. Carcinogenic heterocyclic amines in model systems and cooked foods: a review on formation, occurrence and intake. Food and Chemical Toxicology 1998; 36(9-10): 879-96.

16 Larsson BK, Sahlberg GP, Eriksson AT, Busk LA. Polycyclic aromatic hydrocarbons in grilled food. Journal of Agricultural and Food Chemistry 1983; 31(4): 867-73.

17 Cross AJ, Pollock JR, Bingham SA. Haem, not protein or inorganic iron, is responsible for endogenous intestinal $\mathrm{N}$-nitrosation arising from red meat. Cancer Research 2003; 63(10): 2358-60

18 Echarte M, Ansorena D, Astiasaran I. Fatty acid modifications and cholesterol oxidation in pork loin during frying at different temperatures. Journal of Food Protection 2001; 64(7): 1062-6.

19 Glei M, Latunde-Dada GO, Klinder A, Becker TW, Hermann $\mathrm{U}$, Voigt $\mathrm{K}$, et al. Iron-overload induces oxidative DNA damage in the human colon carcinoma cell line HT29 clone 19A. Mutation Research 2002; 519(1-2): 151-61.

20 Osada K, Hoshina S, Nakamura S, Sugano M. Cholesterol oxidation in meat products and its regulation by supplementation of sodium nitrite and apple polyphenol before processing. Journal of Agricultural and Food Chemistry 2000; 48(9): 3823-9.

21 Paniangvait P, King AJ, Jones AD, German BG. Cholesterol oxides in foods of animal origin. Journal of Food Science 1995; 60: $1159-74$

22 Linseisen J, Wolfram G, Miller AB. Plasma $7 \beta$-hydroxycholesterol as a possible predictor of lung cancer risk. Cancer Epidemiology, Biomarkers \& Prevention 2002; 11(12): 1630-7.

23 Riboli E, Hunt KJ, Slimani N, Ferrari P, Norat T, Fahey M, et al. European Prospective Investigation into Cancer and Nutrition (EPIC): study populations and data collection. Public Health Nutrition 2002; 5(6B): 1113-24

24 Slimani N, Kaaks R, Ferrari P, Casagrande C, Clavel-Chapelon F, Lotze G, et al. European Prospective Investigation into Cancer and Nutrition (EPIC) calibration study: rationale, design and population characteristics. Public Health Nutrition 2002; 5(6B): 1125-45.

25 Slimani N, Deharveng G, Charrondiere RU, van Kappel AL, Ocke MC, Welch A, et al. Structure of the standardized computerized 24-h diet recall interview used as reference method in the 22 centers participating in the EPIC project. European Prospective Investigation into Cancer and Nutrition. Computer Methods and Programs in Biomedicine 1999; 58(3): 251-66.

26 Linseisen J, Kesse E, Slimani N, Bueno-De-Mesquita HB, Ocke MC, Skeie G, et al. Meat consumption in the European Prospective Investigation into Cancer and Nutrition (EPIC) cohorts: results from 24-hour dietary recalls. Public Health Nutrition 2002; 5(6B): 1243-58.

27 Rohrmann S, Linseisen J, Becker N, Norat T, Sinha R, Skeie G, et al. Cooking of meat and fish in Europe - results from the European Prospective Investigation into Cancer and Nutrition (EPIC). European Journal of Clinical Nutrition 2002; 56(12): 1216-30.

28 Ferrari P, Slimani N, Ciampi A, Trichopoulou A, Naska A, Lauria C, et al. Evaluation of under- and overreporting of energy intake in the 24-hour diet recalls in the European
Prospective Investigation into Cancer and Nutrition (EPIC). Public Health Nutrition 2002; 5(6B): 1329-45.

29 Lijinsky W. N-Nitroso compounds in the diet. Mutation Research 1999; 443(1-2): 129-38.

30 Haorah J, Zhou L, Wang X, Xu G, Mirvish SS. Determination of total $N$-nitroso compounds and their precursors in frankfurters, fresh meat, dried salted fish, sauces, tobacco, and tobacco smoke particulates. Journal of Agricultural and Food Chemistry 2001; 49(12): 6068-78.

31 Bingham SA, Hughes R, Cross AJ. Effect of white versus red meat on endogenous $N$-nitrosation in the human colon and further evidence of a dose response. Journal of Nutrition 2002; 132(Suppl. 11): 3522S-5S.

32 Rowland IR, Granli T, Bockman OC, Key PE, Massey RC. Endogenous $N$-nitrosation in man assessed by measurement of apparent total $N$-nitroso compounds in faeces. Carcinogenesis 1991; 12(8): 1395-401.

33 Penttila PL, Rasanen L, Kimppa S. Nitrate, nitrite, and $\mathrm{N}$ nitroso compounds in Finnish foods and the estimation of the dietary intakes. Zeitschrift fur Lebensmittel-Untersuchung und -Forschung 1990; 190(4): 336-40.

34 Lowik MR. Possible use of food consumption surveys to estimate exposure to additives. Food Additives and Contaminants 1996; 13(4): 427-41.

35 Honikel KO. The Use of Additives in Meat Products Throughout Europe. Necessity, Customs, Legislation. Utrecht: ECCEAMST, 1995.

36 Dich J, Jarvinen R, Knekt P, Penttila PL. Dietary intakes of nitrate, nitrite and NDMA in the Finnish Mobile Clinic Health Examination Survey. Food Additives and Contaminants 1996; 13(5): 541-52.

37 Meah MN, Harrison N, Davies A. Nitrate and nitrite in foods and the diet. Food Additives and Contaminants 1994; 11(4): 519-32.

38 Vaessen HA, Schothorst RC. The oral nitrate and nitrite intake in The Netherlands: evaluation of the results obtained by HPIC analysis of duplicate 24-hour diet samples collected in 1994. Food Additives and Contaminants 1999; 16(5): 181-8.

39 Borawska M, Markiewicz R, Witkowska A. Nitrate and nitrite content in daily hospital diets during the winter season comparison of analytical and calculation methods. European Journal of Clinical Nutrition 1998; 52(7): 489-93.

40 Parkin DM, Whelan SL, Ferlay J, Raymond L, eds. Cancer Incidence in Five Continents. Vol. II. Lyon: International Agency for Research on Cancer, 1997.

41 Palli D. Epidemiology of gastric cancer: an evaluation of available evidence. Journal of Gastroenterology 2000; 35(Suppl. 12): 84-9.

42 Simko P. Determination of polycyclic aromatic hydrocarbons in smoked meat products and smoke flavouring food additives. Journal of Chromatography. B, Analytical Technologies in the Biomedical and Life Sciences 2002; 770(1-2): 3-18.

43 Hu J, Mao Y, Dryer D, White K. Canadian Cancer Registries Epidemiology Research Group. Risk factors for lung cancer among Canadian women who have never smoked. Cancer Detection and Prevention 2002; 26(2): 129-38.

44 Ji BT, Chow WH, Gridley G, Mclaughlin JK, Dai Q, Wacholder S, et al. Dietary factors and the risk of pancreatic cancer: a case-control study in Shanghai China. Cancer Epidemiology, Biomarkers \& Prevention 1995; 4(8): 885-93.

45 Sanchez-Diez A, Hernandez-Mejia R, Cueto-Espinar A. Study of the relation between diet and gastric cancer in a rural area of the Province of Leon, Spain. European Journal of Epidemiology 1992; 8(2): 233-7.

46 Probst-Hensch NM, Sinha R, Longnecker MP, Witte JS, Ingles SA, Frankl HD, et al. Meat preparation and colorectal adenomas in a large sigmoidoscopy-based case-control study in California (United States). Cancer Causes \& Control 1997; 8(2): 175-83. 
47 Butler LM, Sinha R, Millikan RC, Martin CF, Newman B, Gammon MD, et al. Heterocyclic amines, meat intake, and association with colon cancer in a population-based study. American Journal of Epidemiology 2003; 157(5): 434-45.

48 Sinha R, Kulldorff M, Curtin J, Brown CC, Alavanja MC, Swanson CA. Fried, well-done red meat and risk of lung cancer in women (United States). Cancer Causes \& Control 1998; 9(6): 621-30.

49 Sinha R, Gustafson DR, Kulldorff M, Wen WQ, Cerhan JR, Zheng W. 2-Amino-1-methyl-6-phenylimidazo[4,5-b]pyridine, a carcinogen in high-temperature-cooked meat, and breast cancer risk. Journal of the National Cancer Institute 2000; 92(16): 1352-4.

50 Zheng W, Gustafson DR, Sinha R, Cerhan JR, Moore D, Hong $\mathrm{CP}$, et al. Well-done meat intake and the risk of breast cancer. Journal of the National Cancer Institute 1998; 90(22): $1724-9$.

51 Ward MH, Sinha R, Heineman EF, Rothman N, Markin R, Weisenburger DD, et al. Risk of adenocarcinoma of the stomach and esophagus with meat cooking method and doneness preference. International Journal of Cancer 1997; 71(1): 14-9.

52 Norrish AE, Ferguson LR, Knize MG, Felton JS, Sharpe SJ, Jackson RT. Heterocyclic amine content of cooked meat and risk of prostate cancer. Journal of the National Cancer Institute 1999; 91(23): 2038-44.

53 Cross AJ, Peters U, Hayes RB, Andriole GL, Reding D, Sinha R. Heterocyclic amines formed in meat cooked at high temperatures may increase prostate cancer risk. Paper presented at the 95th Annual Meeting of the American Association for Cancer Research, Orlando, FL, 27-31 March 2004; 45

54 Le Marchand L, Hankin JH, Pierce LM, Sinha R, Nerurkar PV, Franke AA, et al. Well-done red meat, metabolic phenotypes and colorectal cancer in Hawaii. Mutation Research 2002; 506-507: 205-14.
55 Sinha R, Kulldorff M, Swanson CA, Curtin J, Brownson RC, Alavanja MC. Dietary heterocyclic amines and the risk of lung cancer among Missouri women. Cancer Research 2000; 60(14): 3753-6.

56 Augustsson K, Skog K, Jagerstad M, Dickman PW, Steineck G. Dietary heterocyclic amines and cancer of the colon, rectum, bladder, and kidney: a population-based study. Lancet 1999; 353(9154): 703-7.

57 Kangsadalampai K, Butryee C, Manoonphol K. Direct mutagenicity of the polycylic aromatic hydrocarboncontaining fraction of smoked and charcoal-broiled foods treated with nitrite in acid solution. Food and Chemical Toxicology 1997; 35(2): 213-8.

58 Deneo-Pellegrini H, De Stefani E, Boffetta P, Ronco A, Mendilaharsu M. Dietary iron and cancer of the rectum: a case-control study in Uruguay. European Journal of Cancer Prevention 1999; 8(6): 501-8.

59 Kato I, Dnistrian AM, Schwartz M, Toniolo P, Koenig K, Shore $\mathrm{RE}$, et al. Iron intake, body iron stores and colorectal cancer risk in women: a nested case-control study. International Journal of Cancer 1999; 80(5): 693-8.

60 Wurzelmann JI, Silver A, Schreinemachers DM, Sandler RS, Everson RB. Iron intake and the risk of colorectal cancer. Cancer Epidemiology, Biomarkers \& Prevention 1996; 5(7): 503-7.

61 Sesink AL, Termont DS, Kleibeuker JH, Van der Meer R. Red meat and colon cancer: the cytotoxic and hyperproliferative effects of dietary heme. Cancer Research 1999; 59(22): 5704-9.

62 Smith-Warner SA, Ritz J, Hunter DJ, Albanes D, Beeson WL, van den Brandt PA, et al. Dietary fat and risk of lung cancer in a pooled analysis of prospective studies. Cancer Epidemiology, Biomarkers \& Prevention 2002; 11(10 Pt 1): 987-92.

63 Schroepfer GJ Jr. Oxysterols: modulators of cholesterol metabolism and other processes. Physiological Review 2000; 80(1): $361-554$ 